\title{
Bed boundary identification from well log data using Walsh transform technique: A case study from NGHP Expedition-02 in the Krishna-Godavari basin, India
}

\author{
Bappa Mukherjee ${ }^{1}$ and Kalachand Sain ${ }^{1,2, *}$ \\ ${ }^{1}$ Seismic Group, CSIR-National Geophysical Research Institute, Uppal Road, Hyderabad 500007 , India. \\ ${ }^{2}$ Wadia Institute of Himalayan Geology, 33, General Mahadeo Singh Road, Dehradun 248 001, India. \\ *Corresponding author. e-mail: kalachandsain7@gmail.com
}

MS received 31 July 2018; revised 27 May 2019; accepted 4 June 2019

Identification of thin stratigraphic beds is often dealt with using the scale of core data analysis. The downhole wireline log data also provide accurate information on the characteristics of lithological boundaries. In the present study, we have used a Walsh low pass filter and bed boundary detection algorithm to develop an automated bed boundary identification approach. Initially, we ran a Walsh low pass filter against the wireline log responses. Afterwards, a bed boundary detection algorithm has been applied to the Walsh low pass filtered version of the wireline log data. The Walsh domain filter creates a stepped version of the well log data having a constant step width over the entire low pass version of the log signal. As the Walsh function basically represents the binary waveforms, the Walsh low pass filtering can appropriately identify the thin lithological units within a complex succession of sedimentary strata. Further, the proposed approach is an efficient way of resolving and understanding subsurface inhomogeneity from wireline log data. The feasibility of the technique is successfully tested on the downhole wireline log data acquired from the Krishna-Godavari basin during the Expedition 02 of Indian National Gas Hydrate Program (MGHP).

Keywords. Borehole geophysics; Walsh transforms; bed boundary; KG basin; NGHP-02.

\section{Introduction}

Discrimination of bed boundary is an essential step of geophysical and geological interpretation in reservoir analysis. Generally, the interpreters use their experiences and geological knowledge in traditional wireline log interpretation, and sometimes provide different interpretation from the same data (Dewan 1983; Hsieh et al. 2005). The geophysical $\log$ response is a measurement of petrophysical properties through which the borehole is drilled. Each kind of log data provides a particular physical property of the formation (Das and Chatterjee 2018; Gogoi and Chatterjee 2018). Several non- conventional techniques are proposed and established for bed boundary detection from wireline log data. Lanning and Johnson (1983) have applied the Walsh low pass filter to other log data, and identified the bed boundaries using a bed boundary detection algorithm. Likewise, an automated approach based on the Walsh transform technique has been used to identify the bed boundaries (Maiti and Tiwari 2005, 2012) and characterise the logs for subsurface lithology (Doveton 1986). Several geophysical problems have been solved by the Walsh transform technique: time-frequency analysis of wireline logs (Jianping et al. 2011), gravity applications (Keating 1992; Shaw et al. 1998), 
resistivity (RES) filtering (Pal 1991) and formation tops identification using gamma-ray (GR) log analysis (Choudhury et al. 2007). The reservoir characterisation study was also documented based on several aspects: Petro-elastic modelling (Auduson 2018), integrated petrophysics and rock physics modelling (Das et al. 2017; Singha and Chatterjee 2017; Wu and Grana 2017); identification of subsurface petrophysical properties using nonlinear regression analysis (Aboosadi et al. 2018); real bed boundary identification from well log data (Khoshbakht et al. 2017). Schlumberger has developed the borehole imaging tools like Formation MicroScanner (FMS) and Fullbore Formation MicroImager (FMI), which have the ability in discriminating the beds based on centimetre scales (Gaillot et al. 2007; Singha and Chatterjee 2015; Ali et al. 2017; Chatterjee et al. 2017). In petroleum industries, these expensive tools (FMS and FMI) are used for some specific purposes. The intention of the present study is to find out the plausible thick and thin beds from conventional wireline log data with a view to provide a general assessment of bed boundary successions in a robust manner with less computation time and cost.
We have employed the Walsh low pass filter along with the boundary picking algorithm to the GR, RES and bulk density (RHOB) log data for delineating the bed boundaries. The wireline log data with the sampling interval of $0.1524 \mathrm{~m}$ from four boreholes (NGHP-02-17-C, NGHP-02-19-C, NGHP-02-22-C and NGHP-02-23-C) drilled in the Krishna-Godavari basin (KG basin) during the National Gas Hydrate Program Expedition 02 (NGHP Exp-02) have been used in this study.

\section{Walsh filters and bed boundary detection algorithm}

The Walsh function is a set of complete and orthogonal functions of the non-sinusoidal waveform. In contrast to sinusoidal waveforms whose amplitudes may assume any value between +1 and - 1 (Beauchamp 1975), the Walsh functions assume only the discrete amplitudes that provide the kernel function of the Walsh transform, which is simpler and faster than the Fourier transform. Harmuth (1968) has introduced the concept of generalised frequency in the Walsh transform, called as the sequency, equivalent to frequency in

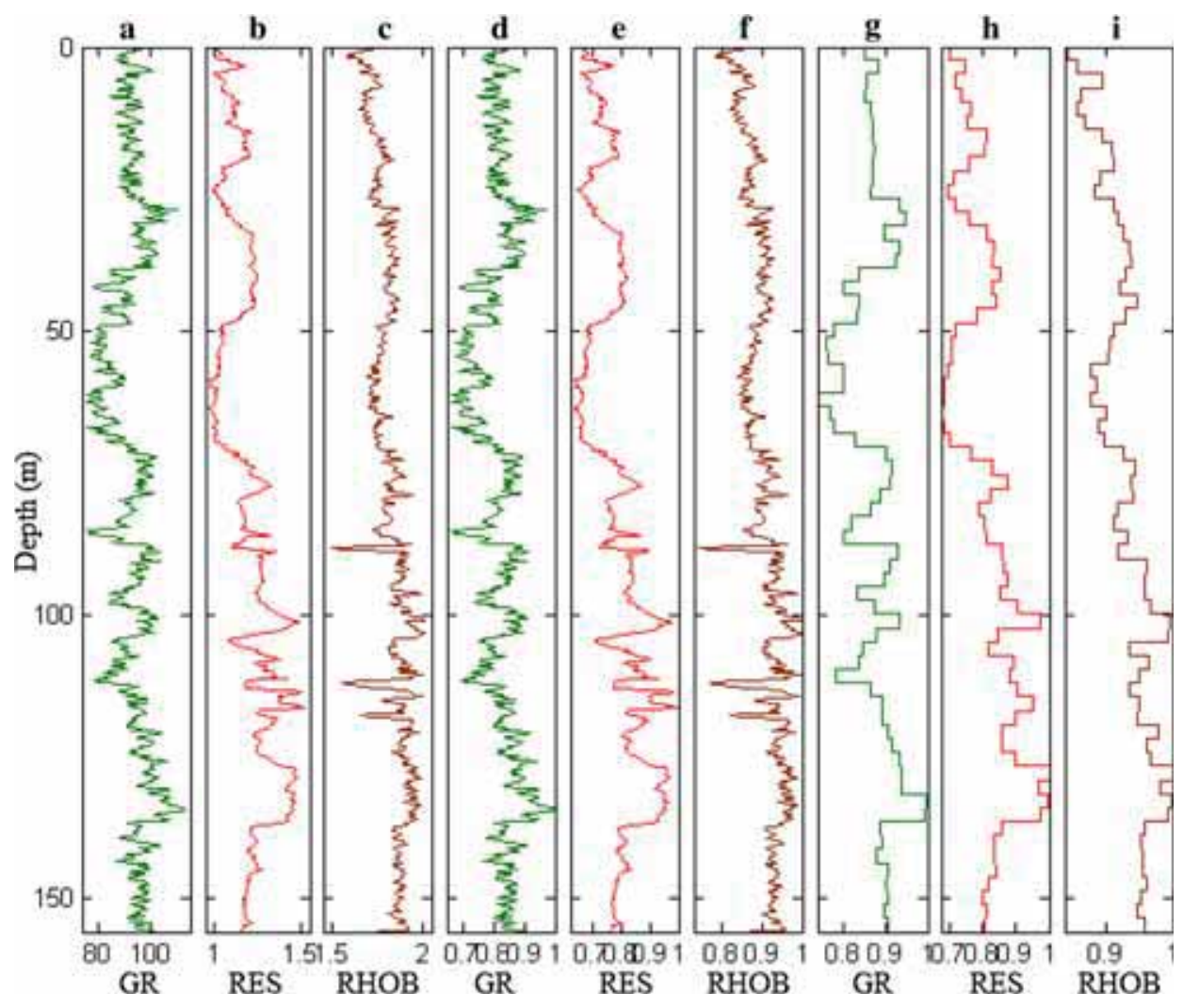

Figure 1. Synthetic wireline log response: (a) GR log, (b) RES log, (c) RHOB log; normalised version of synthetic log response: (d) GR log, (e) RES log, (f) RHOB log; Walsh low pass version of synthetic log response: (g) GR log, (h) RES log, (i) RHOB log. 
the Fourier transform. The term 'sequency' is defined as the half of the average number of zeros crossing in a unit interval (time or space). The unit for sequency is zeros per second (zps). The complete set of the Walsh function can be derived through the difference equation as:

$$
\begin{aligned}
& \text { Wal }(2 k+q, x) \\
& =(-1)^{[k / 2]+q}\left\{\text { wal }(k, 2 x)+(-1)^{[k+q]}\right. \\
& \operatorname{wal}(k, 2(x-1 / 2))\} \quad \text { for } 0 \leq x \leq 1, \\
& =0 \quad \text { for } 0>x>1,
\end{aligned}
$$

where $q=0$ or 1 and $k=0,1,2, \ldots$ correspond to the sequency of the Walsh functions (Beauchamp 1975). Walsh functions are subdivided into even and odd functions, called as cosine-like Walsh function, denoted by $\mathrm{Cal}(k, x)$ and sine-like Walsh function, denoted by $\operatorname{Sal}(k, x)$ respectively, i.e.,

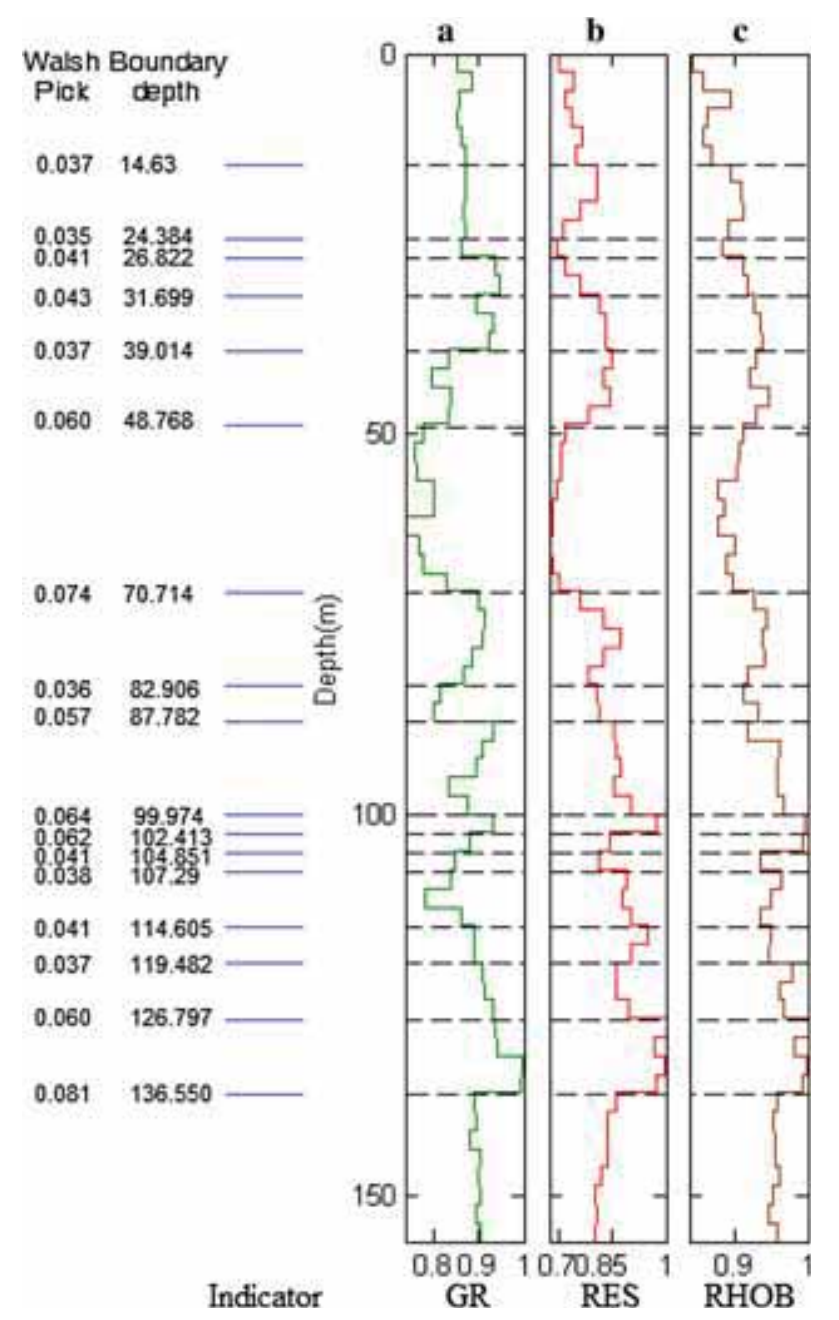

Figure 2. Walsh low pass picked boundaries over the low pass version of synthetic log response for Walsh check value of 0.035 .

$$
\text { Cal }(k, x)=\text { wal }(2 k, x)
$$

and

$$
\text { Sal }(k, x)=\text { wal }(2 k-1, x) .
$$

A function $f(x)$, defined in the interval $(-1,1)$ that satisfies the Dirichlet's conditions, can be represented by an infinite series of Walsh functions as (Shaw and Agarwal 1990)

$$
f(x)=\sum_{k=0}^{\infty} F(k) \text { wal }(k, x),
$$

where

$$
F(k)=\int_{-1 / 2}^{1 / 2} f(x) \text { wal }(k, x) \mathrm{d} x .
$$

For eventually spaced sequence $\{x(i)\}$ of $N$ number of data sets, the discrete Walsh transform is defined as

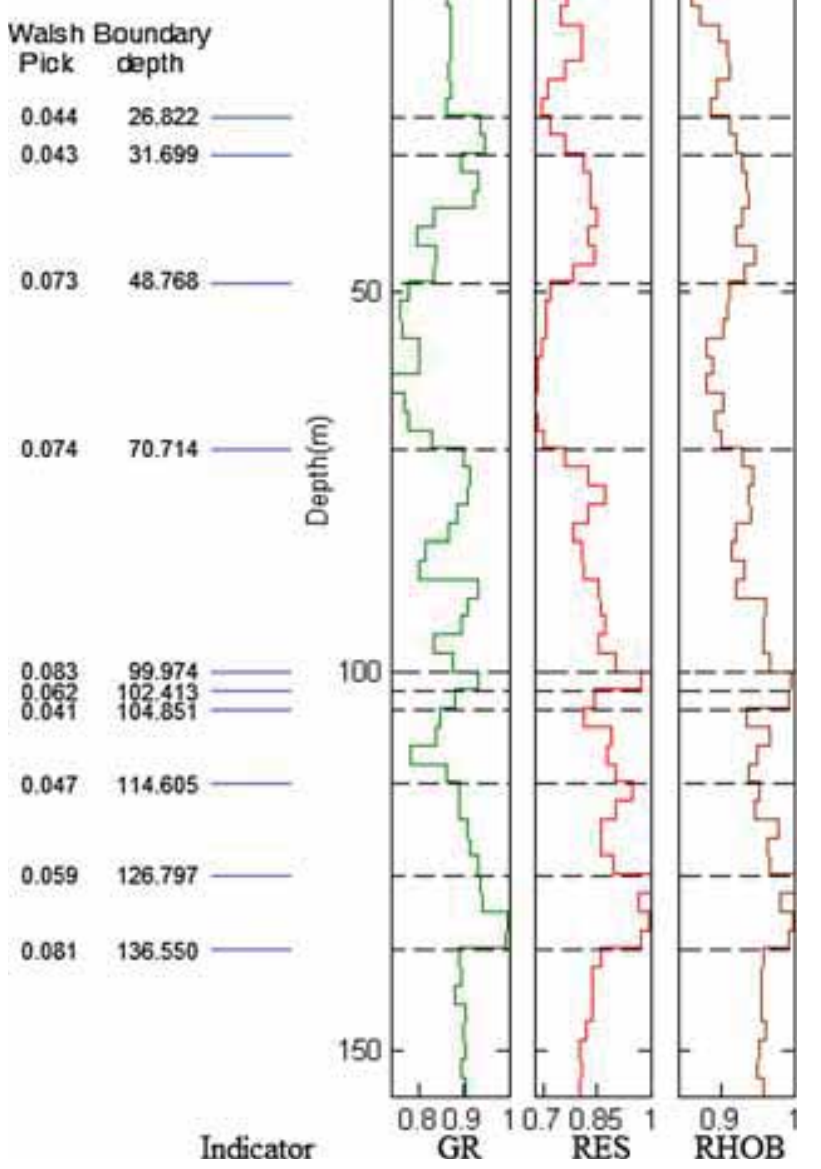

Figure 3. Walsh low pass picked boundaries over the low pass version of synthetic log response for Walsh check value of 0.04 . 


$$
X(k)=\frac{1}{N} \sum_{i=0}^{N-1} x(i) \operatorname{wal}(k, i)
$$

and $x(i)$ can be obtained as

$$
x(i)=\sum_{k=0}^{N-1} X(k) \mathrm{wal}(k, i) .
$$

The discrete Walsh transform is mathematically correct, but computationally may not be efficient while dealing with a large number of data points. There are $N^{2}$ operations involved; for practical purposes, the fast Walsh transform reduces the number of operations to $N \log _{2} N$. The Walsh transform is an innovative mathematical tool that does not experience the Gibbs phenomena (Bath 1974) and need any specific window in the time domain. As per the Walsh filtering technique, the filter coefficients are set to either 0 or 1 (Harmuth 1968). Keating (1992) observed in Walsh low pass filtering that all sequences above a certain threshold are multiplied by 0 or 1 . The Walsh low pass versions of the wireline log data have been used to obtain the rock boundary (Lanning and Johnson 1983). Similar algorithms have also been applied to detect the bed boundary in an automated approach (Maiti and Tiwari 2005; Mukherjee and Roy 2016). Lanning and Johnson (1983) used the depth corresponding to the beginning of log data points as a first boundary value, which may not be true. Thus, we have modified the approach; however, the first step may not always be the boundary and therefore, we call it as the mean boundary value. Afterwards, one of the low pass versions of the logs was considered and the absolute magnitude difference between the present and the mean of the previous

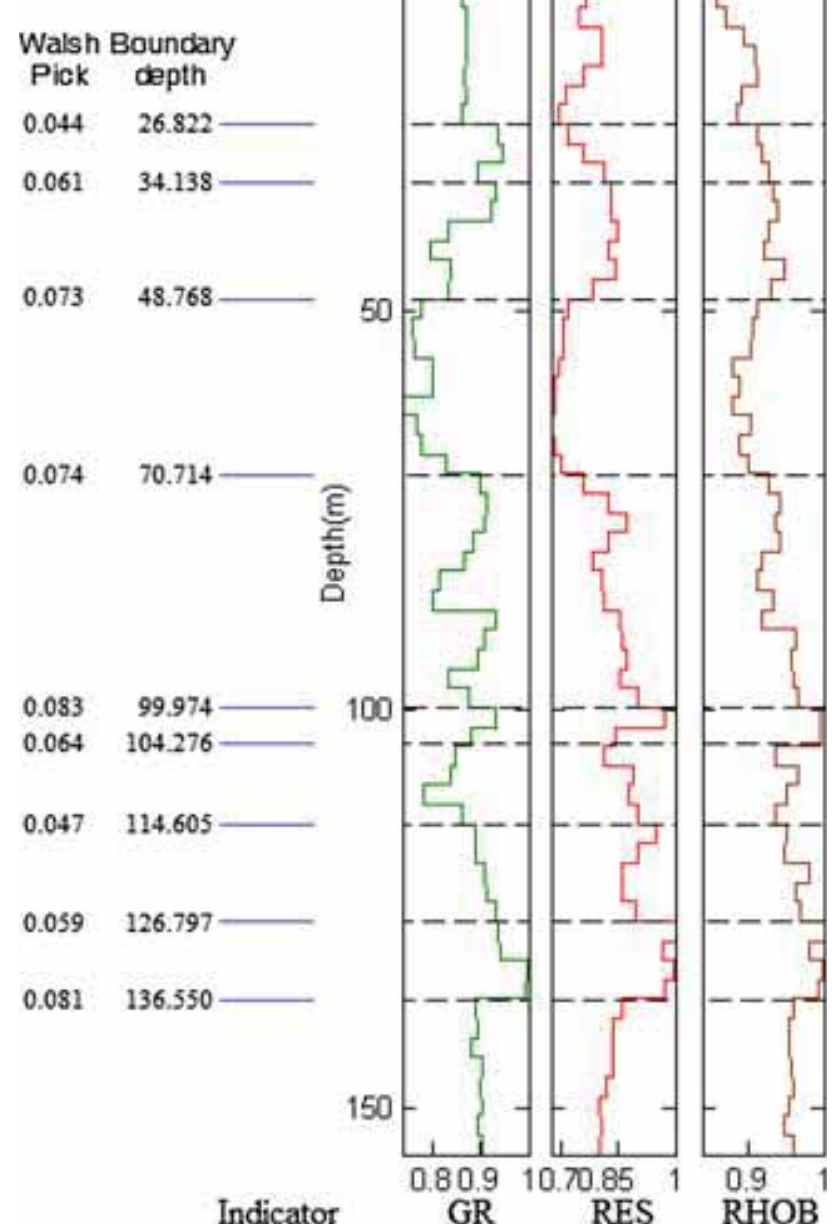

Figure 4. Walsh low pass picked boundaries over the low pass version of synthetic log response for Walsh check value of 0.045 .

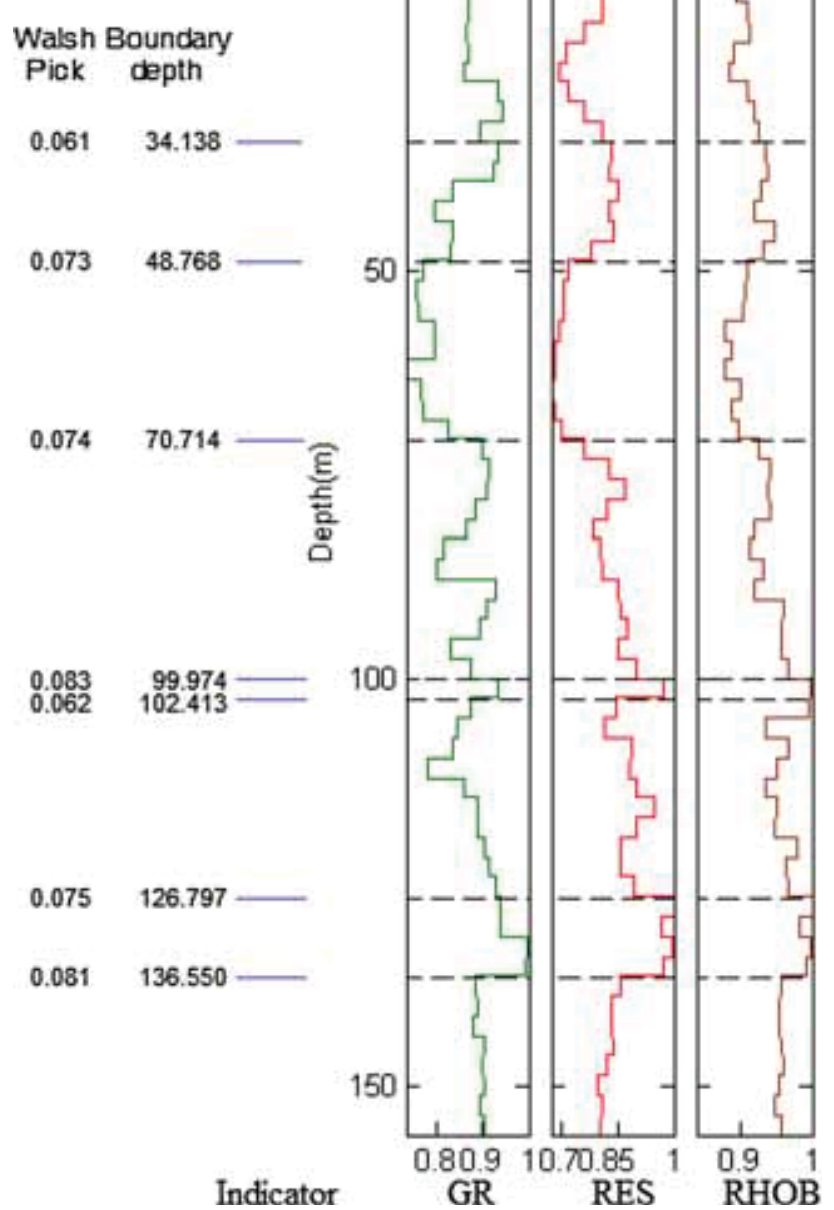

Figure 5. Walsh low pass picked boundaries over the low pass version of synthetic log response for Walsh check value of 0.05 . 


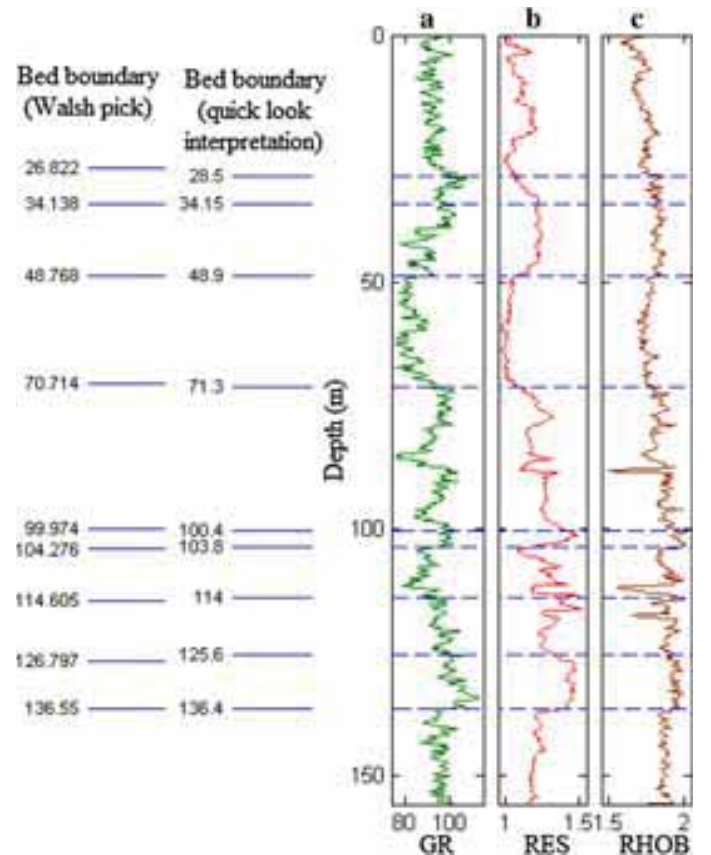

Figure 6. Comparison of bed boundaries obtained from a quick-look interpretation and Walsh boundary picking algorithm (for the check value of 0.045 ). value are computed for all previous steps. These absolute differences were calculated for all log data simultaneously and each of them was multiplied by a weighting value and results are summed as to form the Walsh pick value. It is a non-dimensional quantity which measures the amount of variation taking place simultaneously on all low pass versions of $\log$ data. The term Walsh pick value is compared with another non-dimensional number called 'Check' (carefully selected by the interpreter). 'Check' value is also a dimensionless number, we have to choose the check value in such a way, if the Walsh pick is greater or equal to the Check value, then the depth at the beginning of the step is detected as a bed boundary, or else a new boundary has not been crossed and the procedure is repeated. Within the MATLAB code, we can change this check value; according to the selection of this check value, the number of detected boundaries will change. We have to finalise the optimum numbers of beds, which provides geologically meaningful information. Moreover, the

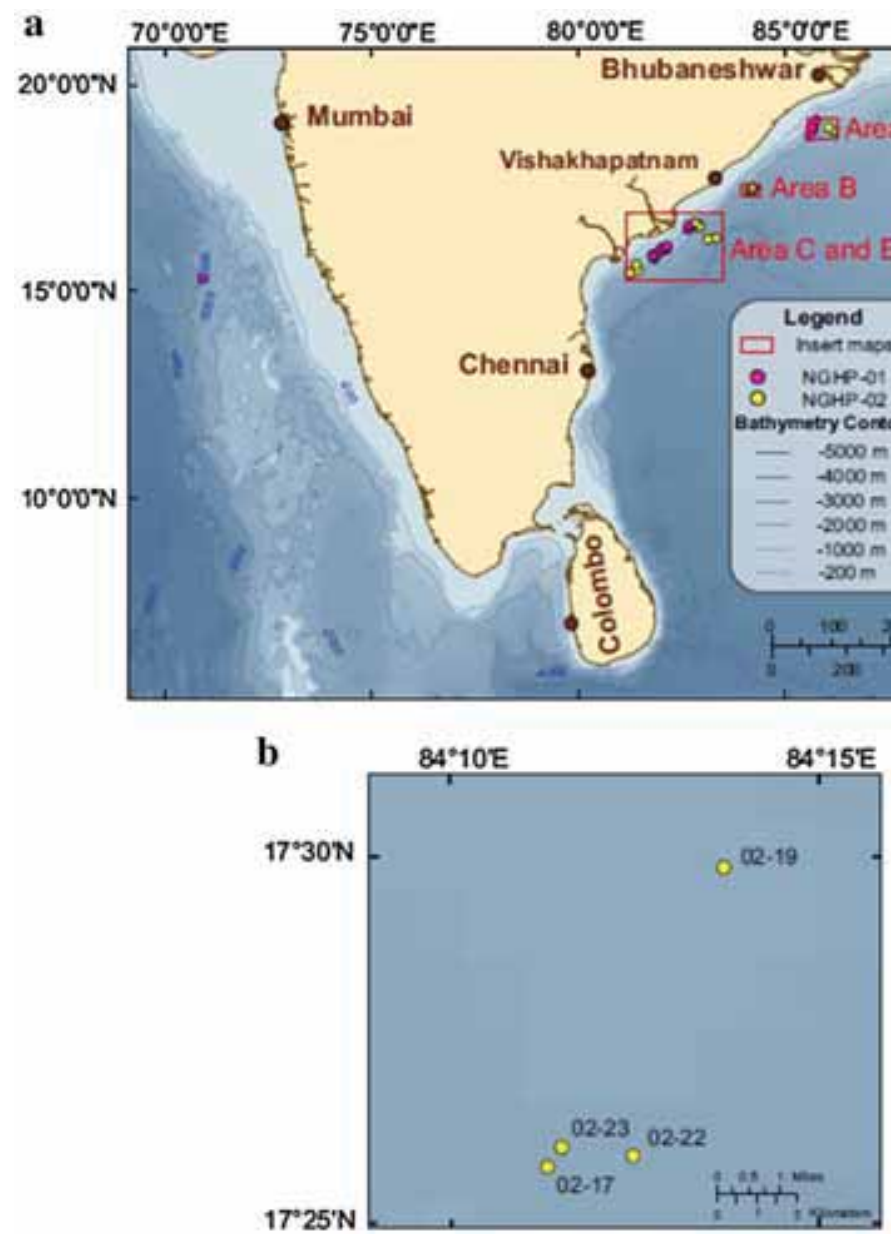

Figure 7. (a) Study area and location of drill sites of NGHP-01 and NGHP-02. (b) Location of the holes NGHP-02-17-C to NGHP-02-23-C in the KG basin. 
'check' value controls the sensitivity of the analysis. The proposed technique cannot detect the beds with thickness less than the step width. In Walsh low pass filtering operation, the step width is an adjustable quantity and it is a function of the cut-off sequency. As per the methodology applied by Lanning and Johnson (1983), the lower the cut-off sequency, the wider the step-width of the Walsh low pass data. The quantity step-width (=total bandwidth/width of the low pass band),

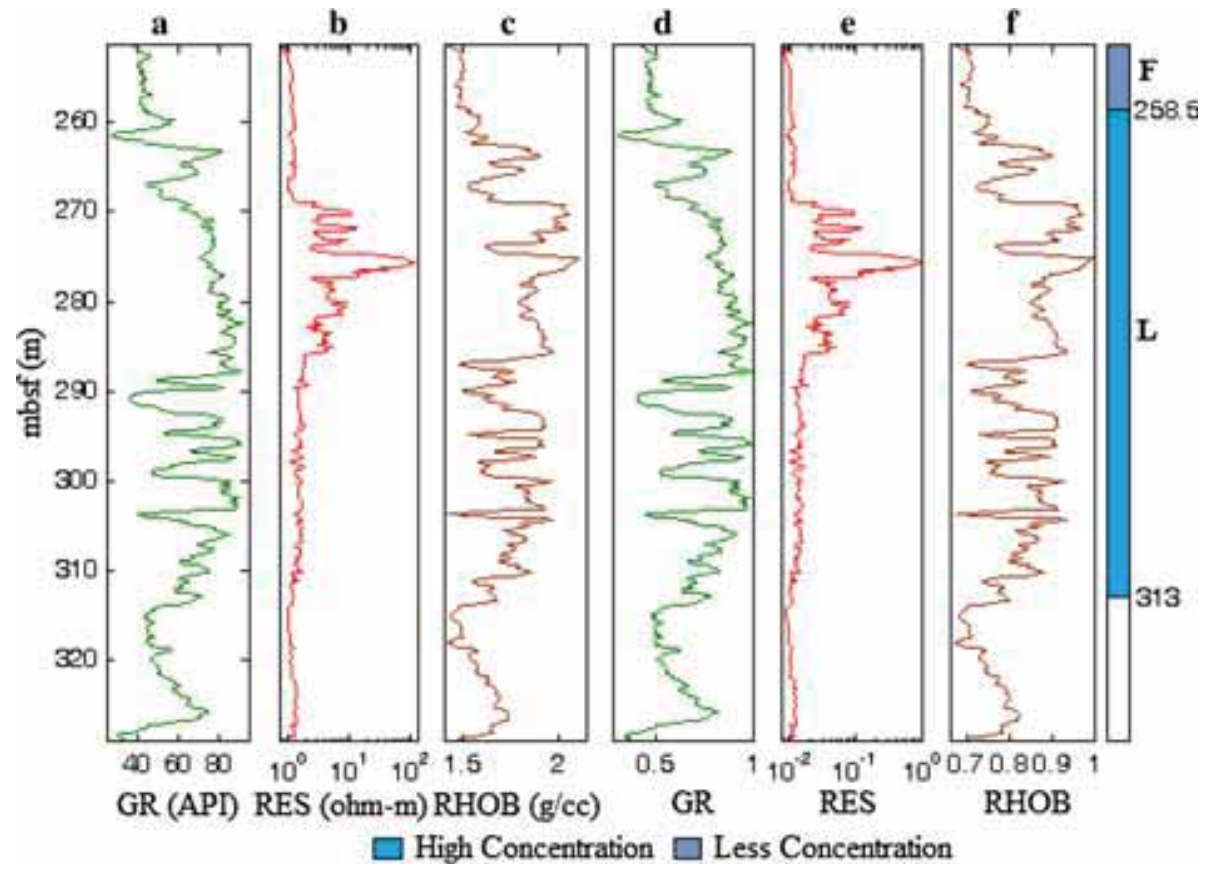

Figure 8. Representation of wireline log responses at hole NGHP-02-17-C and their normalised version: (a) GR log, (b) RES log, (c) RHOB log, (d) normalised GR, (e) normalised RES and (f) normalised RHOB, where F indicates the fracture type gas hydrate zone and $\mathrm{L}$ indicates the layered type gas hydrate zone.

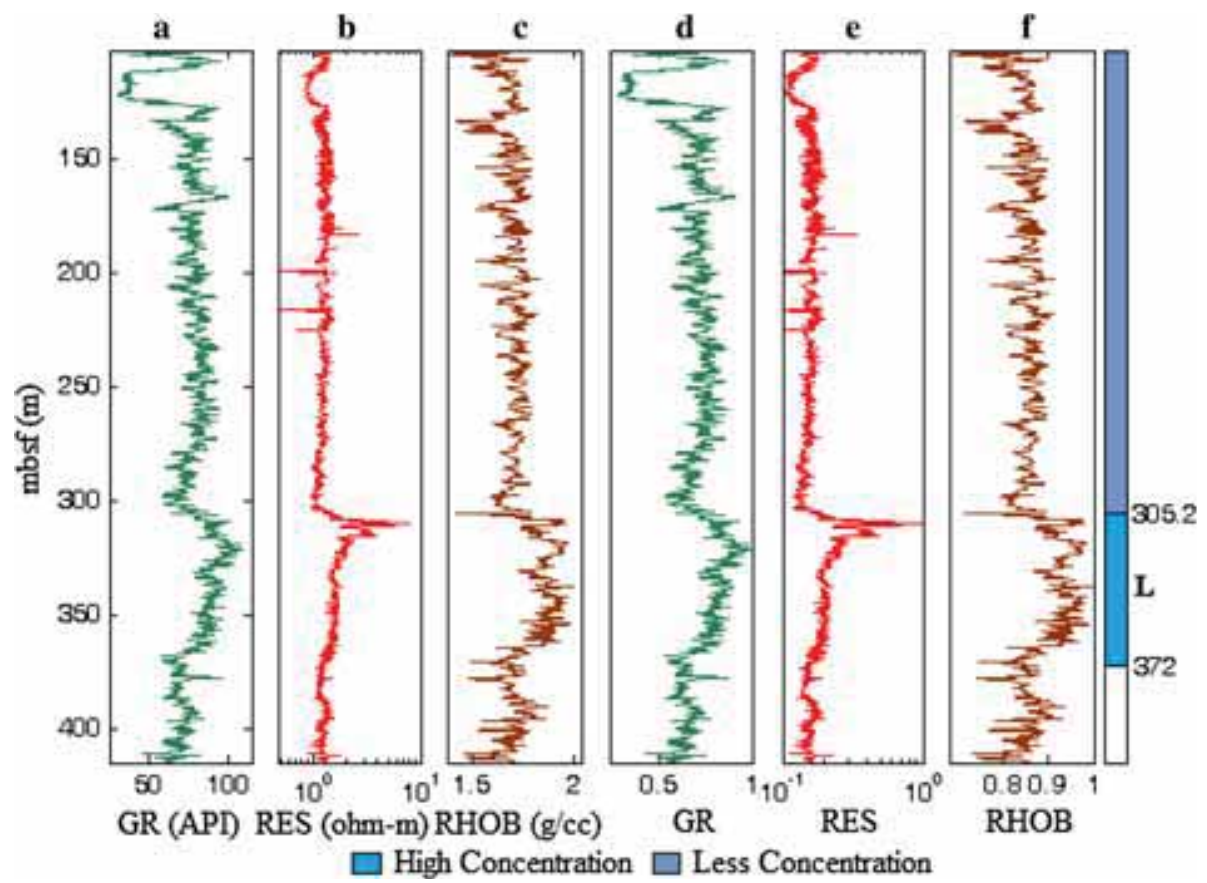

Figure 9. Representation of wireline log responses at hole NGHP-02-19-C and their normalised version: (a) GR log, (b) RES log, (c) RHOB log, (d) normalised GR, (e) normalised RES and (f) normalised RHOB, where L indicates the layered type gas hydrate zone. 
which is constant if the cut-off sequency is varied from $2^{N-1}+1$ to $2^{N}$, where $N$ is the number of data points. To check the sensitivity of the methodology, we have carried the whole analysis on instantly generated synthetic wireline $\log$ responses. The synthetic logs, normalised version of synthetic logs and Walsh low pass version of the normalised synthetic logs are shown in figure 1. Next, we have obtained the bed boundaries from Walsh low pass version of the normalised synthetic logs by employing the different Check values such as 0.035, 0.04, 0.045 and 0.05 , are shown in figures $2-5$, respectively. It is seen that the boundaries obtained for the Check value 0.045 provide optimum number of boundaries and more or less corroborated with the boundary obtained from the quick-look interpretation, as shown in figure 6 .

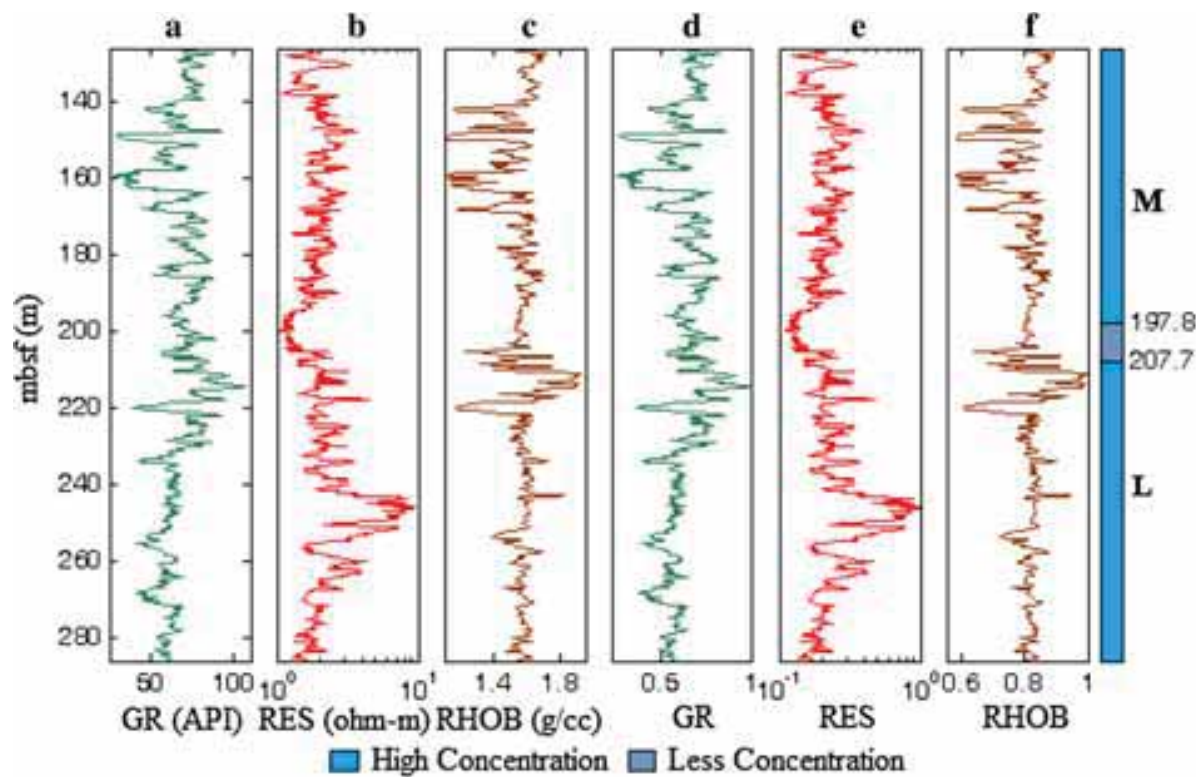

Figure 10. Representation of wireline log responses at hole NGHP-02-22-C and their normalised version: (a) GR log, (b) RES log, (c) RHOB log, (d) normalised GR, (e) normalised RES and (f) normalised RHOB, where M indicates mixed layered and fracture type gas hydrate zone and $\mathrm{L}$ indicates layered type gas hydrate zone.

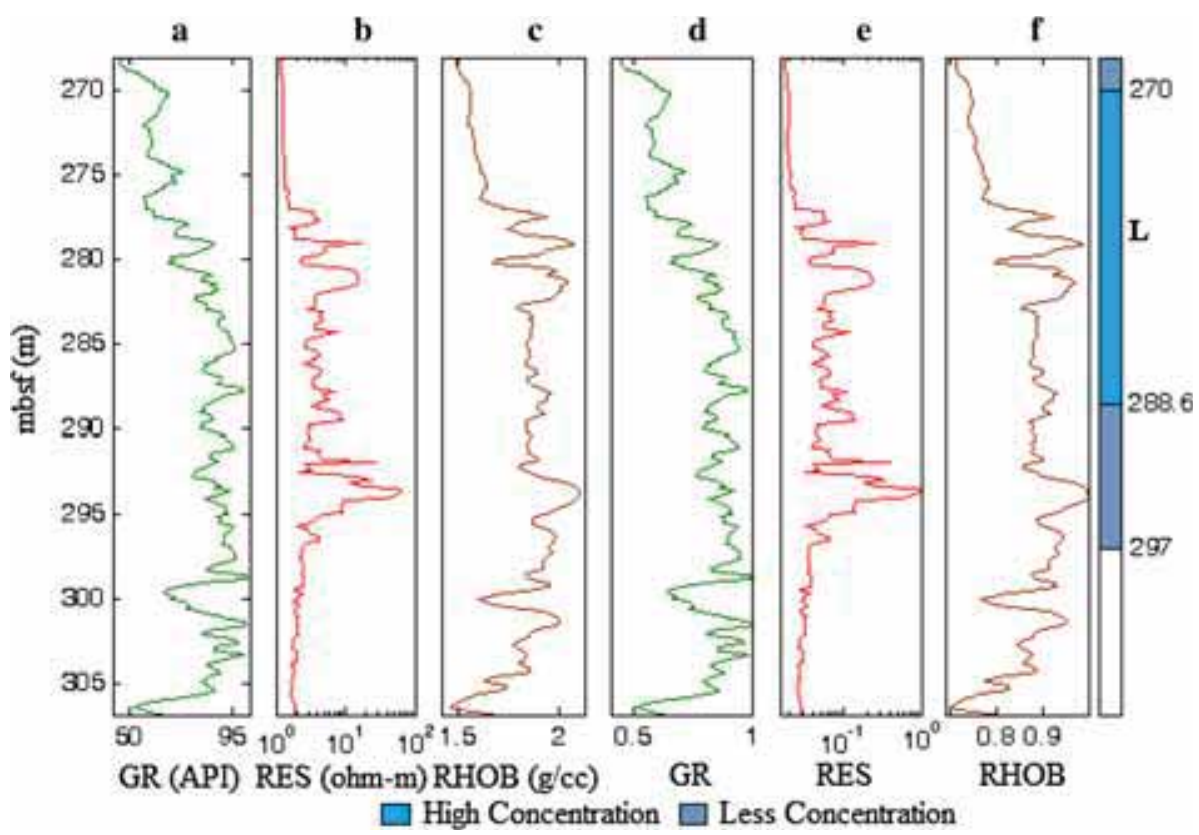

Figure 11. Representation of wireline log responses at hole NGHP-02-23-C and their normalised version: (a) GR log, (b) RES $\log$, (c) RHOB log, (d) normalised GR, (e) normalised RES and (f) normalised RHOB, where L indicates layered type gas hydrate zone. 


\section{Case study}

\subsection{Field data}

The KG basin is a well-known petroliferous basin of conventional and non-conventional hydrocarbon
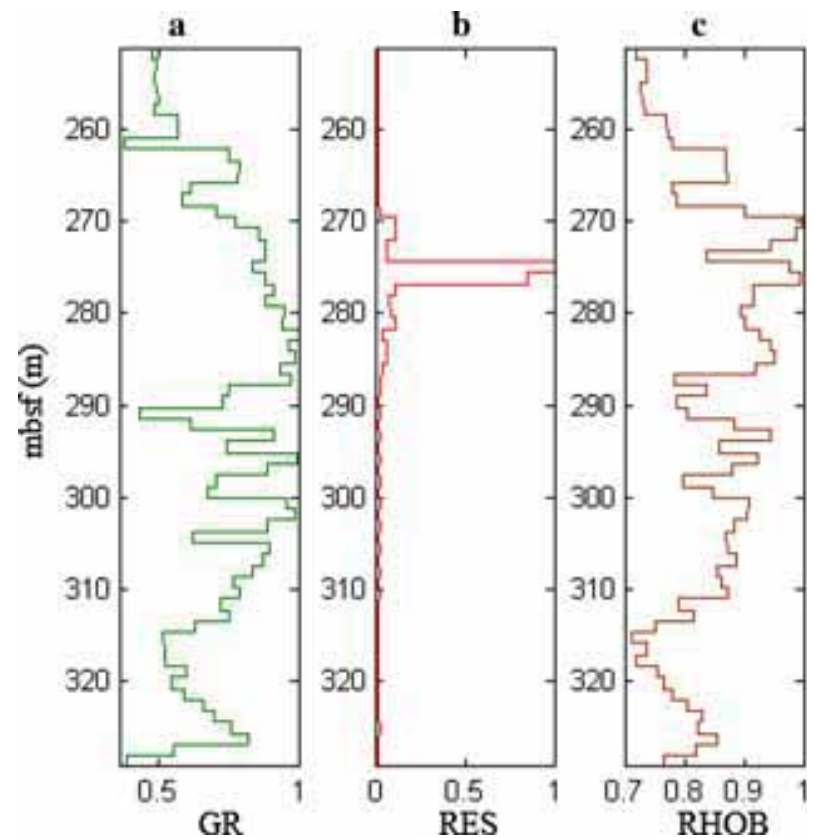

Figure 12. Walsh low pass version of the normalised log responses at hole NGHP-02-17-C: (a) GR log, (b) RES log, (c) RHOB $\log$.

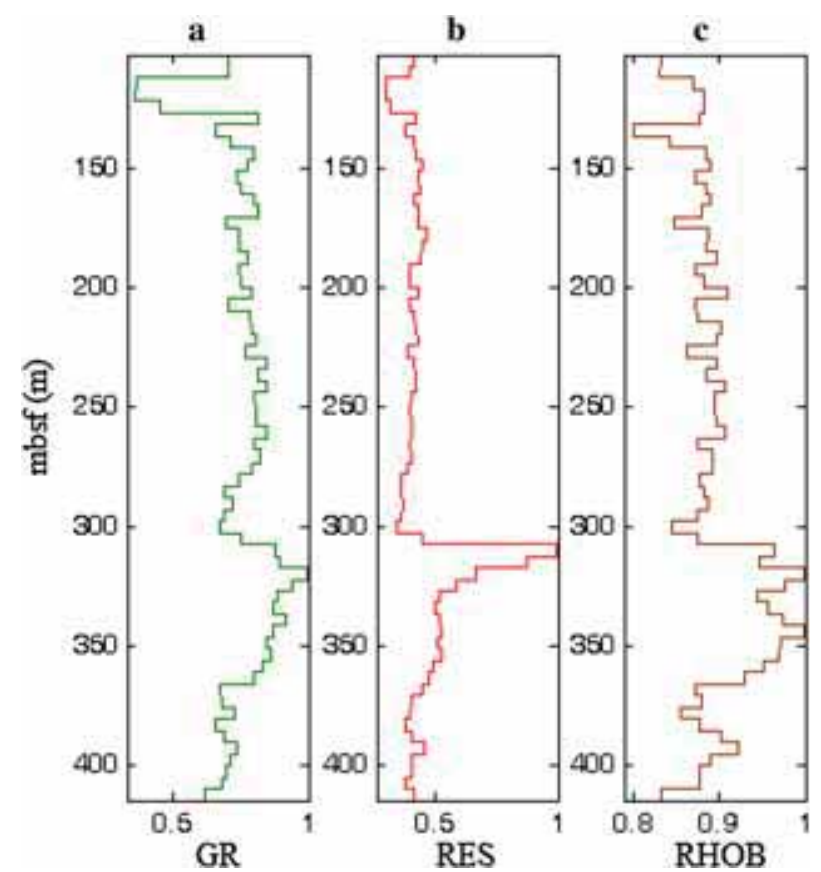

Figure 13. Walsh low pass version of the normalised log responses at hole NGHP-02-19-C: (a) GR log, (b) RES log, (c) RHOB $\log$. resources, situated in the east coast of India. It covers $\sim 15,000 \mathrm{~km}^{2}$ area in the onshore region and $\sim 25,000 \mathrm{~km}^{2}$ area in the offshore region. The wireline log data were acquired during the NGHP Exp-02. The selected study area mainly contains around $5-\mathrm{km}$ thick sediments, belonging to the

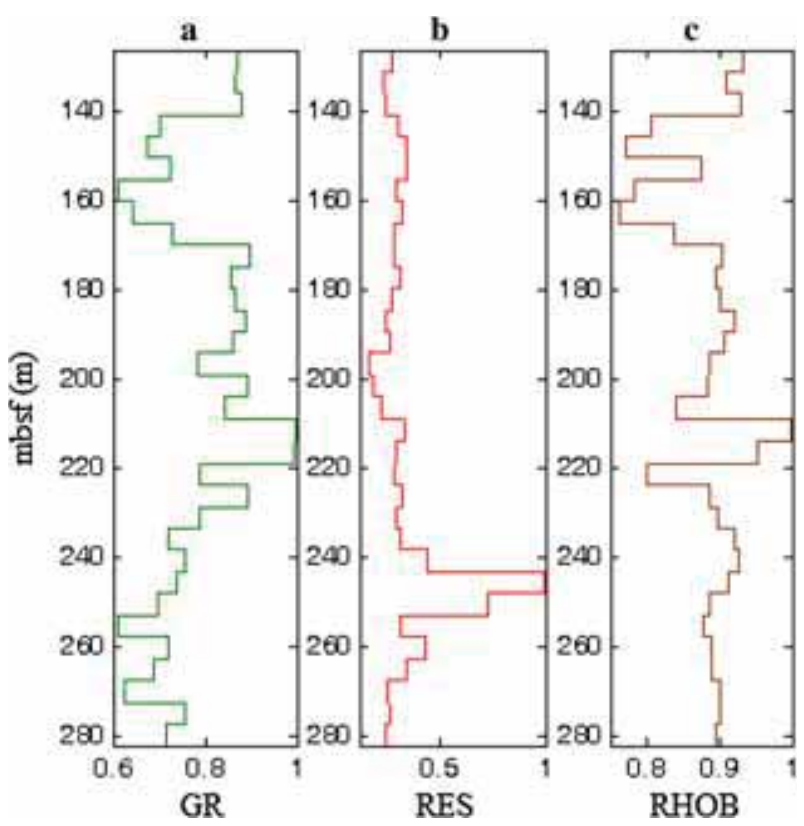

Figure 14. Walsh low pass version of the normalised log responses at hole NGHP-02-22-C: (a) GR log, (b) RES log, (c) RHOB log.

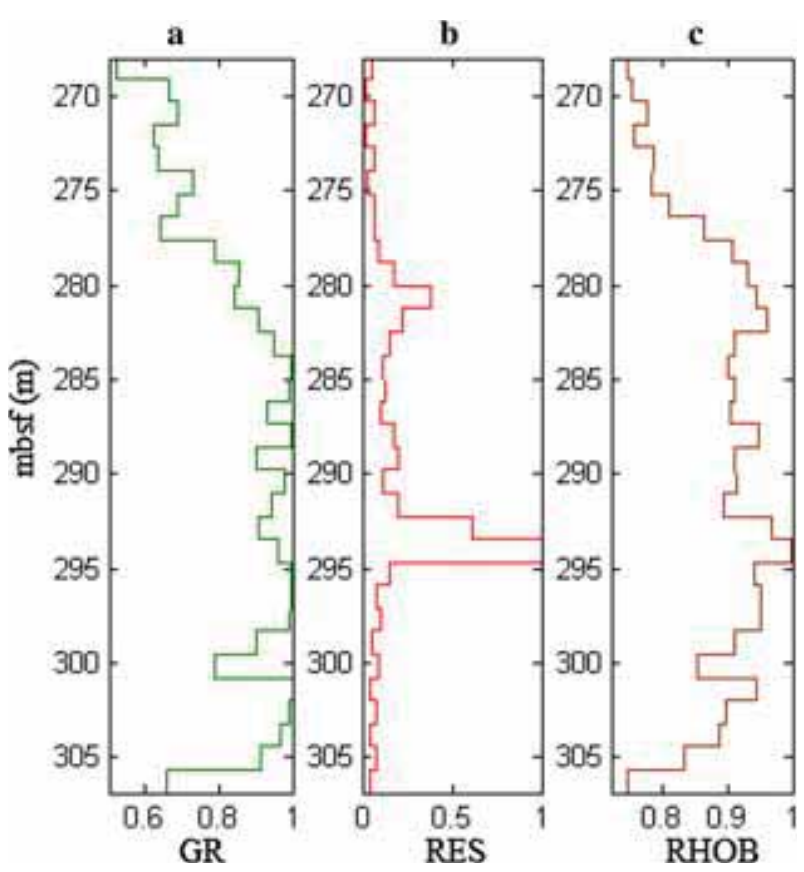

Figure 15. Walsh low pass version of the normalised log responses at hole NGHP-02-23-C: (a) GR log, (b) RES log, (c) RHOB $\log$. 
Late Carboniferous to the Pleistocene age. The sediments are mainly siliciclastic or biogenic, or mixed consisting of soft to hard clays and oozes (Singha et al. 2014). We have taken wireline log responses of the holes NGHP-02-17-C, NGHP-0219-C, NGHP-02-22-C and NGHP-02-23-C. The study area and the location of boreholes are shown in figure $7(\mathrm{a}$ and $\mathrm{b})$. The wireline $\log$ responses (GR, RES, RHOB) along with their normalised versions and details of gas hydrates bearing zones belonging to holes NGHP-02-17-C, NGHP-02-19C, NGHP-02-22-C and NGHP-02-23-C are shown in figures 8-11. The gas hydrate zones (layered type denoted by $\mathrm{L}$, fractured type denoted by $\mathrm{F}$ and mixed zone of layered and fractured type denoted by $\mathrm{M}$ ) are levelled besides the wireline log responses. The core report of NGHP Exp-02 (Kumar et al. 2016) shows five different types of lithology in the selected depth range of boreholes (NGHP-02-17-C, NGHP-02-19-C, NGHP-02-22-C

Table 1. Results of Walsh pick boundary for the borehole NGHP-02-17-C.

\begin{tabular}{lcccc}
\hline $\begin{array}{c}\text { Sl. } \\
\text { no. }\end{array}$ & $\begin{array}{c}\text { Step } \\
\text { width }\end{array}$ & $\begin{array}{c}\text { Walsh pick } \\
\text { value }\end{array}$ & $\begin{array}{c}\text { Walsh pick } \\
\text { boundary }\end{array}$ & $\begin{array}{c}\text { Core } \\
\text { boundary }\end{array}$ \\
\hline 1 & 1.219 & 0.097 & 262.357 & \\
2 & & 0.101 & 269.672 & 270.70 \\
3 & & 0.467 & 274.549 & 274.60 \\
4 & & 0.093 & 275.768 & \\
5 & & 0.394 & 276.987 & \\
6 & & 0.086 & 287.960 & 287.34 \\
7 & & 0.080 & 290.398 & \\
8 & & 0.125 & 292.837 & \\
9 & & 0.071 & 297.714 & \\
10 & & 0.090 & 300.152 & 299.44 \\
11 & & 0.092 & 303.810 & 303.27 \\
12 & 0.074 & 305.029 & \\
13 & 0.073 & 313.563 & \\
14 & & 0.075 & 325.755 & \\
\hline
\end{tabular}

Table 2. Results of Walsh pick boundary for the borehole NGHP-02-19-C.

\begin{tabular}{lcccc}
\hline $\begin{array}{l}\text { Sl. } \\
\text { no. }\end{array}$ & $\begin{array}{c}\text { Step } \\
\text { width }\end{array}$ & $\begin{array}{c}\text { Walsh pick } \\
\text { value }\end{array}$ & $\begin{array}{c}\text { Walsh pick } \\
\text { boundary }\end{array}$ & $\begin{array}{c}\text { Core } \\
\text { boundary }\end{array}$ \\
\hline 1 & 4.876 & 0.154 & 112.513 & \\
2 & & 0.172 & 127.144 & \\
3 & & 0.086 & 132.020 & \\
4 & & 0.320 & 307.585 & 307.61 \\
5 & & 0.167 & 317.339 & \\
6 & & 0.085 & 327.092 & \\
7 & & 0.106 & 366.107 & \\
\hline
\end{tabular}

and NGHP-02-23-C), and these are mainly siltstone, sand, sandy silt, pelagic poor clay and silty sand. Unfortunately, we do not have the sonic velocity and sonic transit time data for the entire selected depth range. Therefore, our study is limited within the depth interval.

Table 3. Results of Walsh pick boundary for the borehole NGHP-02-22-C.

\begin{tabular}{lcccc}
\hline $\begin{array}{c}\text { Sl. } \\
\text { no. }\end{array}$ & $\begin{array}{c}\text { Step } \\
\text { width }\end{array}$ & $\begin{array}{c}\text { Walsh pick } \\
\text { value }\end{array}$ & $\begin{array}{c}\text { Walsh pick } \\
\text { boundary }\end{array}$ & $\begin{array}{c}\text { Core } \\
\text { boundary }\end{array}$ \\
\hline 1 & 4.876 & 0.115 & 140.865 & \\
2 & & 0.115 & 170.126 & \\
3 & & 0.111 & 209.140 & \\
4 & & 0.139 & 218.894 & 217.61 \\
5 & & 0.246 & 243.278 & \\
6 & & 0.114 & 248.155 & \\
7 & & 0.167 & 253.032 & 252.95 \\
\hline
\end{tabular}

Table 4. Results of Walsh pick boundary for the borehole NGHP-02-23-C.

\begin{tabular}{lcccc}
\hline $\begin{array}{l}\text { Sl. } \\
\text { no. }\end{array}$ & $\begin{array}{c}\text { Step } \\
\text { width }\end{array}$ & $\begin{array}{c}\text { Walsh pick } \\
\text { value }\end{array}$ & $\begin{array}{c}\text { Walsh pick } \\
\text { boundary }\end{array}$ & $\begin{array}{c}\text { Core } \\
\text { boundary }\end{array}$ \\
\hline 1 & 1.219 & 0.060 & 269.221 & 269.55 \\
2 & & 0.092 & 277.755 & \\
3 & & 0.114 & 280.194 & 280.45 \\
4 & & 0.088 & 281.413 & 281.28 \\
5 & & 0.062 & 283.851 & 284.00 \\
6 & & 0.218 & 292.386 & \\
7 & & 0.182 & 293.605 & 293.55 \\
8 & & 0.366 & 294.824 & 294.95 \\
9 & & 0.062 & 298.482 & 298.60 \\
10 & & 0.064 & 299.701 & 299.40 \\
11 & & 0.107 & 300.920 & 301.80 \\
12 & & 0.145 & 305.797 & 305.85 \\
\hline
\end{tabular}

Table 5. Weight value assigned to the log response of the studied boreholes.

\begin{tabular}{llcc}
\hline Hole ID & $\begin{array}{c}\text { Log } \\
\text { response }\end{array}$ & $\begin{array}{c}\text { Weight } \\
\text { value }\end{array}$ & $\begin{array}{c}\text { Walsh check } \\
\text { value }\end{array}$ \\
\hline NGHP-02-17-C & GR & 0.25 & 0.070 \\
& $\mathrm{R}_{\mathrm{t}}$ & 0.50 & \\
& RHOB & 0.25 & \\
NGHP-02-19-C & GR & 0.28 & 0.067 \\
& $\mathrm{R}_{\mathrm{t}}$ & 0.45 & \\
& $\mathrm{RHOB}$ & 0.27 & \\
NGHP-02-22-C & GR & 0.33 & 0.080 \\
& $\mathrm{R}_{\mathrm{t}}$ & 0.33 & \\
& $\mathrm{RHOB}$ & 0.34 & \\
NGHP-02-23-C & GR & 0.30 & 0.060 \\
& $\mathrm{R}_{\mathrm{t}}$ & 0.40 & \\
& $\mathrm{RHOB}$ & 0.30 & \\
\hline
\end{tabular}




\subsection{Results and discussion}

The number of data points associated with the boreholes NGHP-02-17-C, NGHP-02-19-C, NGHP02-22-C and NGHP-02-23-C are 512, 2048, 1024 and 256 , respectively. Thus, the cut-off sequency varies from 8 to $5 \mathrm{zpm}$ for 2048 data points. The cut-off sequency varies from 4 to 3 zpm for 1024 data points, and so on. As per our analysis, the step length or step width for the borehole NGHP-02-17-C and NGHP$02-23-\mathrm{C}$ is $1.219 \mathrm{~m}$, whereas it is $4.876 \mathrm{~m}$ for the borehole NGHP-02-19-C and NGHP-02-22-C. The Walsh low pass version of the normalised log responses associated with the boreholes NGHP-0217-C, NGHP-02-19-C, NGHP-02-22-C and NGHP02-23-C are shown in figures 12-15.
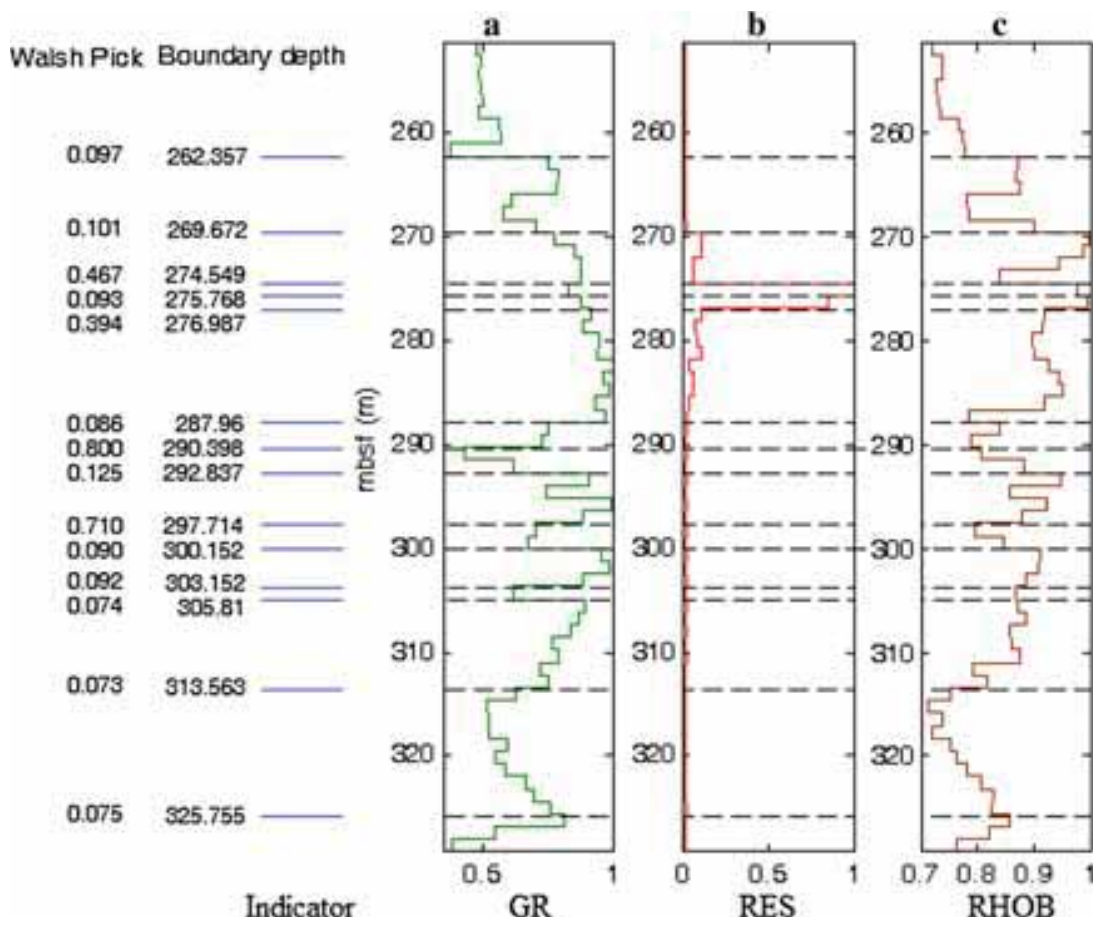

Figure 16. Walsh low pass picked boundaries over the low pass version of wireline log data at hole NGHP-02-17-C.
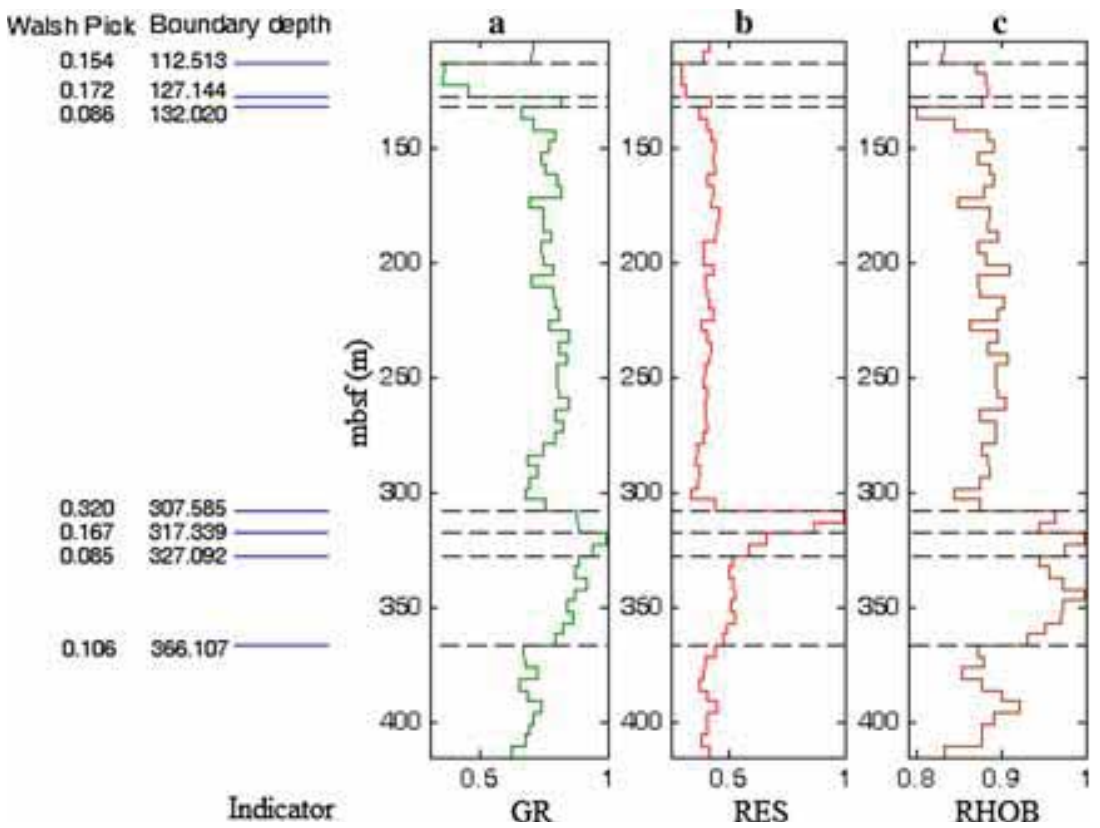

Figure 17. Walsh low pass picked boundaries over the low pass version of wireline log data at hole NGHP-02-19-C. 
Different weights are assigned to different low pass versions of wireline log responses for accomplishing the required amplification, and are shown in tables 1-4, respectively. In the boundary pick algorithm, equal or different weights are assigned to each Walsh low pass version of log data for a particular borehole. Whereas a particular check value is assigned to each of the studied boreholes (table 5). Since the 'check' value controls the sensitivity of the analysis, we have assigned different check values for different wells to obtain the optimum number of beds which can provide geologically meaningful results. Whole analysis has been carried out several times by changing the 'weights'

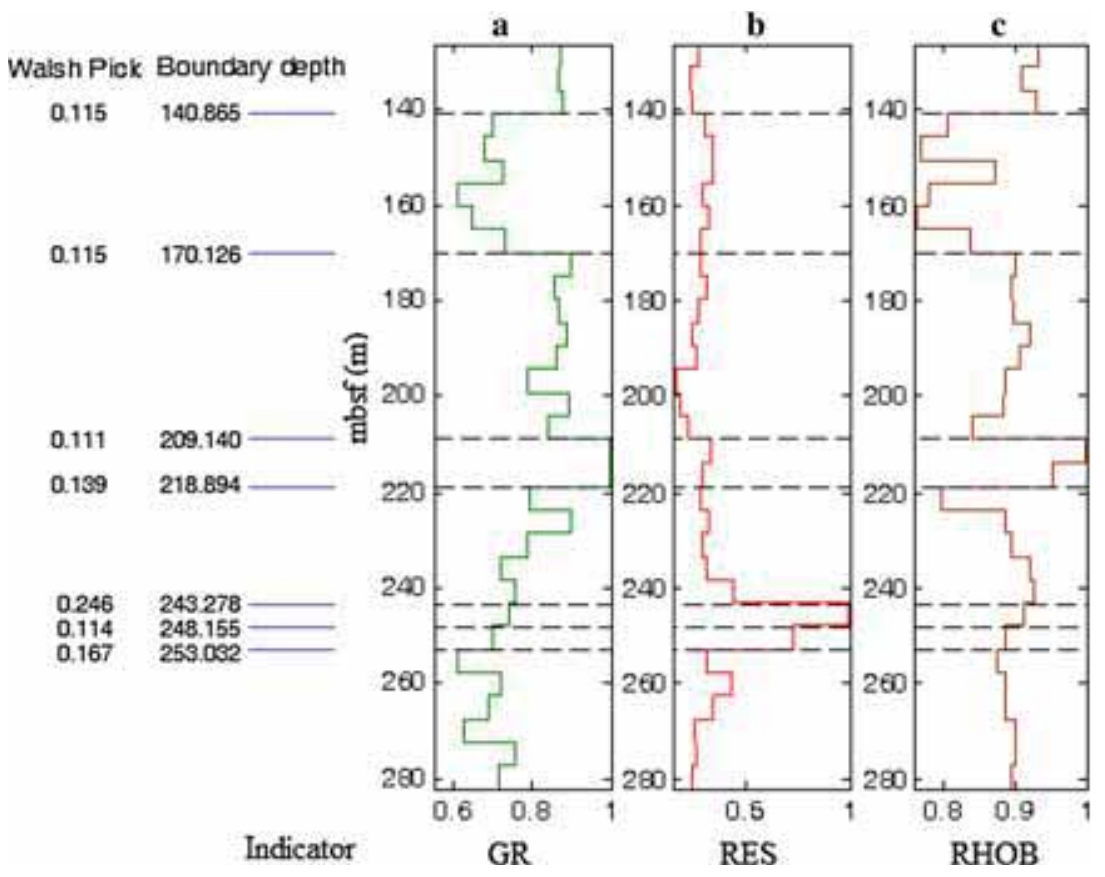

Figure 18. Walsh low pass picked boundaries over the low pass version of wireline log data at hole NGHP-02-22-C.
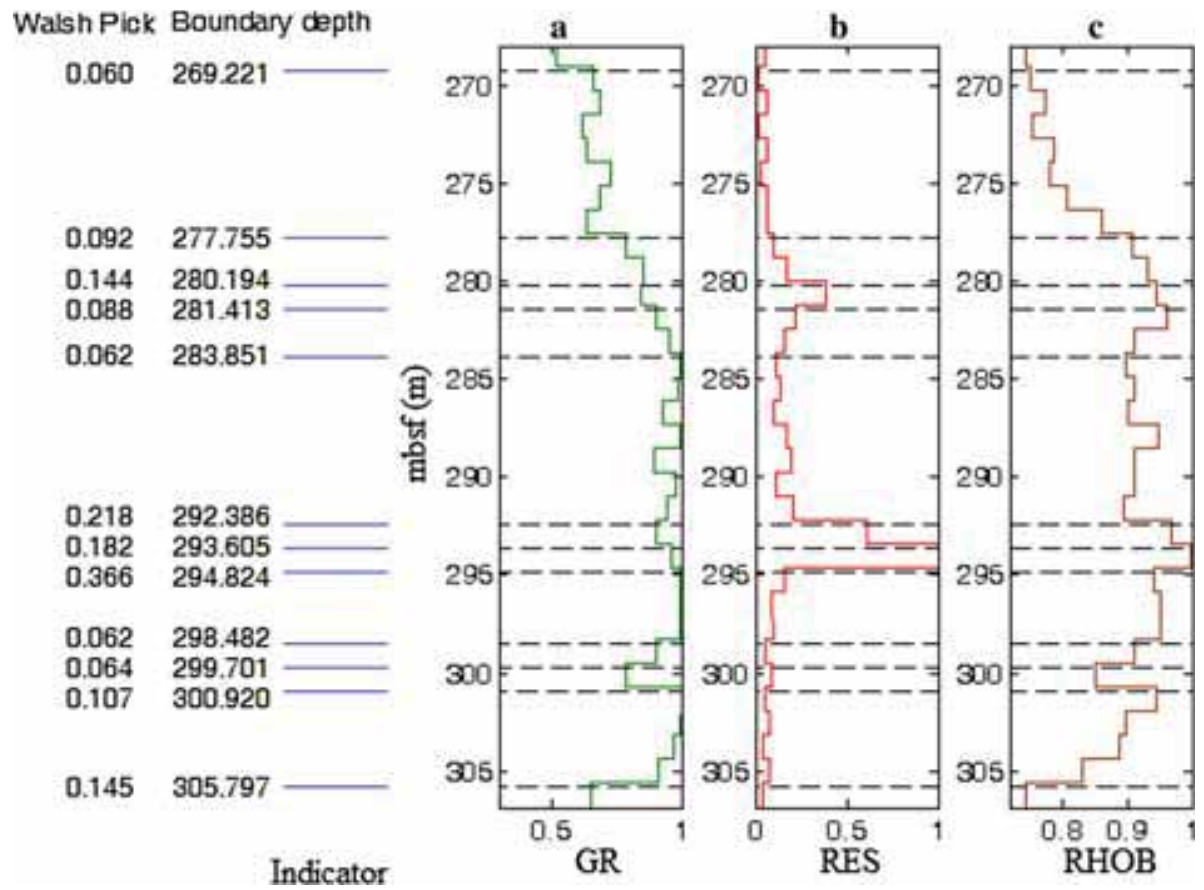

Figure 19. Walsh low pass picked boundaries over the low pass version of wireline log data at hole NGHP-02-23-C. 
and sometimes modifying the Walsh check value to achieve the best results (compared with core boundaries).

As discussed by Lanning and Johnson (1983), the Walsh transform is a real number operation, which does not convey any phase information from the input signal. The estimated low pass versions of the log data have different values in every step.
Hence, if the location of boundary is not exactly situated at the multiple of step length of the Walsh low pass versions, the signal energy associated with the transition between two different beds will be distributed at that step before and after this depth. Therefore, the Walsh boundary detection algorithm can detect the bed boundaries up to the accuracy of one half of the step length. To get the

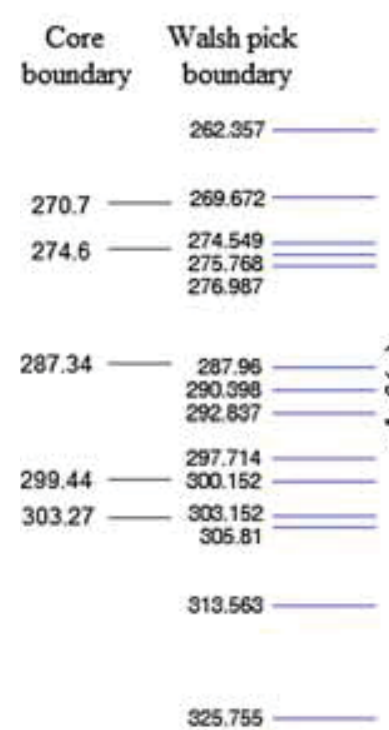

Indicator
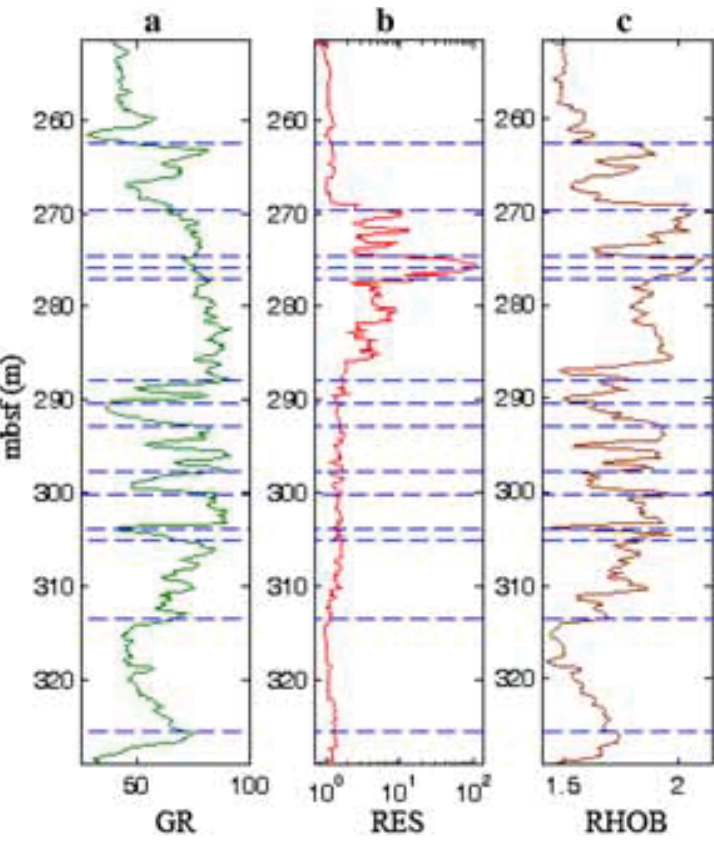

Figure 20. Walsh low pass picked boundaries are plotted over the original log responses at hole NGHP-02-17-C.

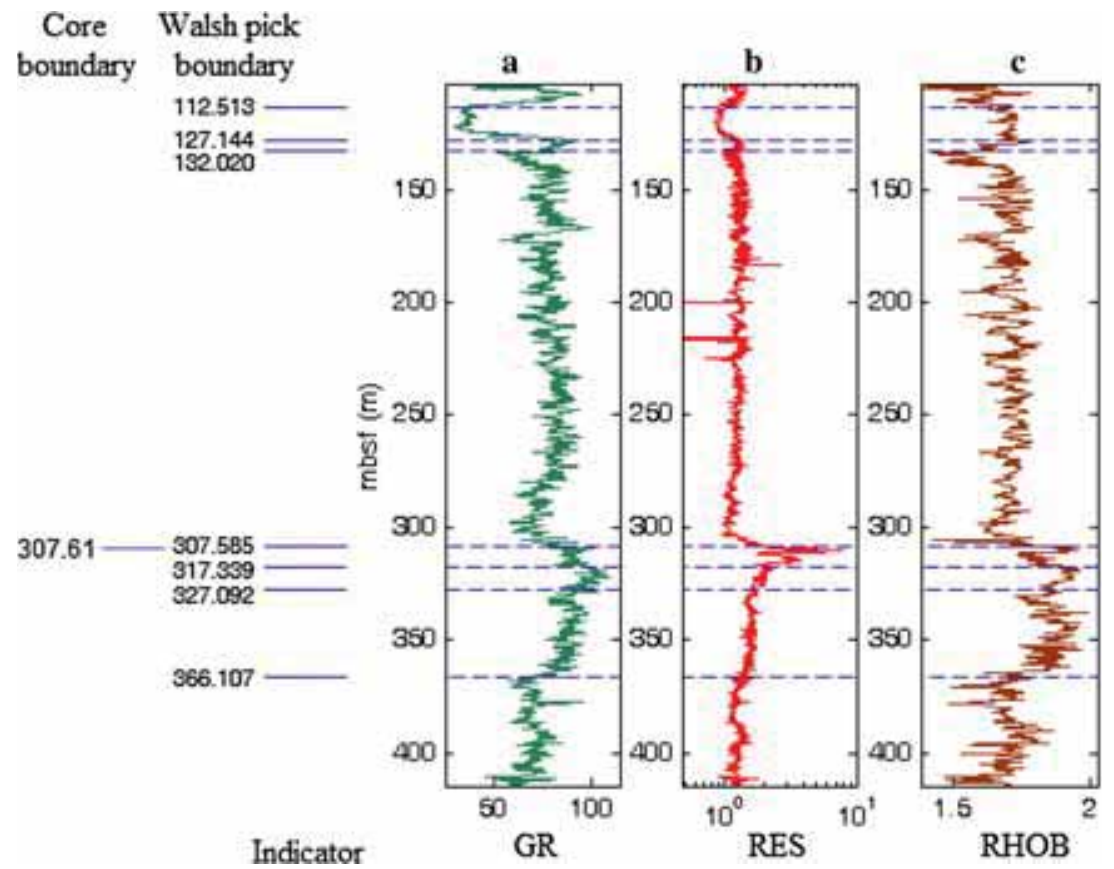

Figure 21. Walsh low pass picked boundaries are plotted over the original log responses at hole NGHP-02-19-C. 
correct depth of the boundary, we have used the formula, suggested by Lanning and Johnson (1983), as

$$
B_{i}=W_{i} \pm \frac{\Delta S}{2}
$$

where $B_{i}$ is the true location of the $i$ th boundary, $W_{i}$ is the Walsh detected boundary and $\Delta S$ is the step length of the Walsh low pass version. Further in second and successive low-pass operations (till end), the distribution of build-up energy depends on the true position of the boundary. Thus, in order to get the true location of the boundary, two sets of boundary can be averaged.

$$
B_{i}=W_{i}^{\prime} \pm \frac{\Delta S}{2}
$$

where $W_{i}^{\prime}$ is the final $i$ th boundary detected by Walsh method. This leads to the resolution improvement by factor two using to successive low

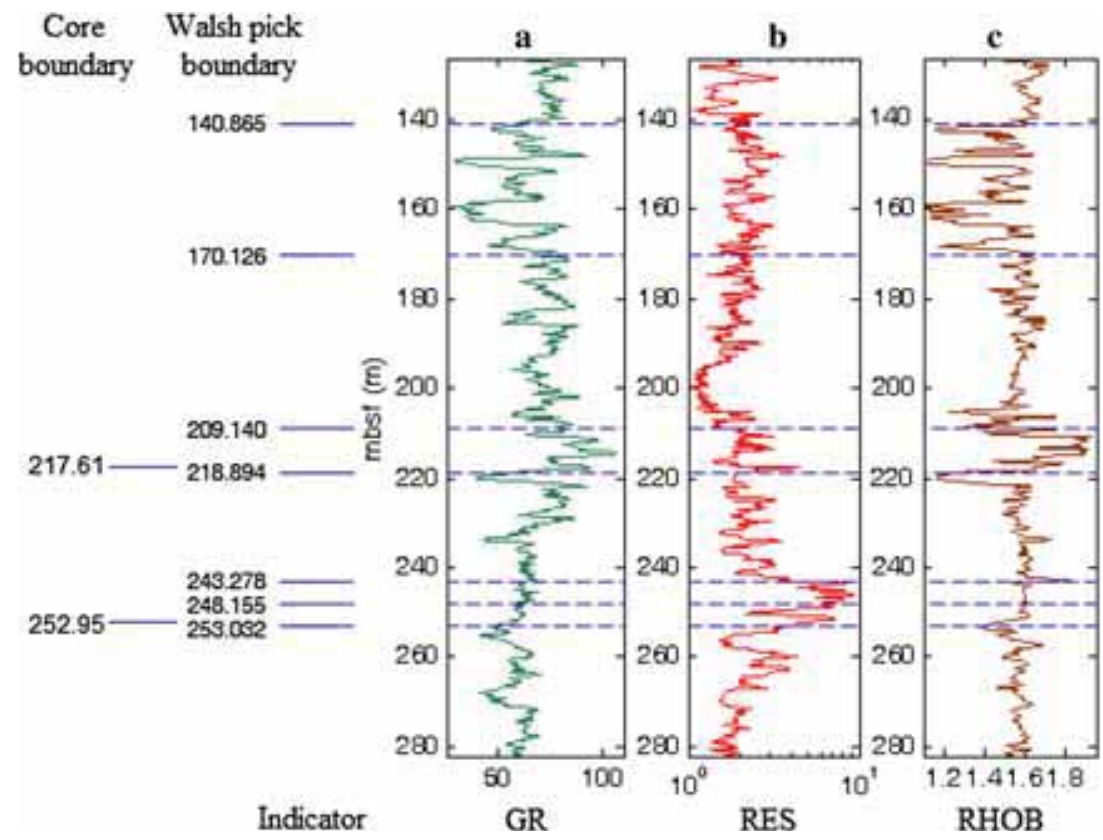

Figure 22. Walsh low pass picked boundaries are plotted over the original log responses at hole NGHP-02-22-C.
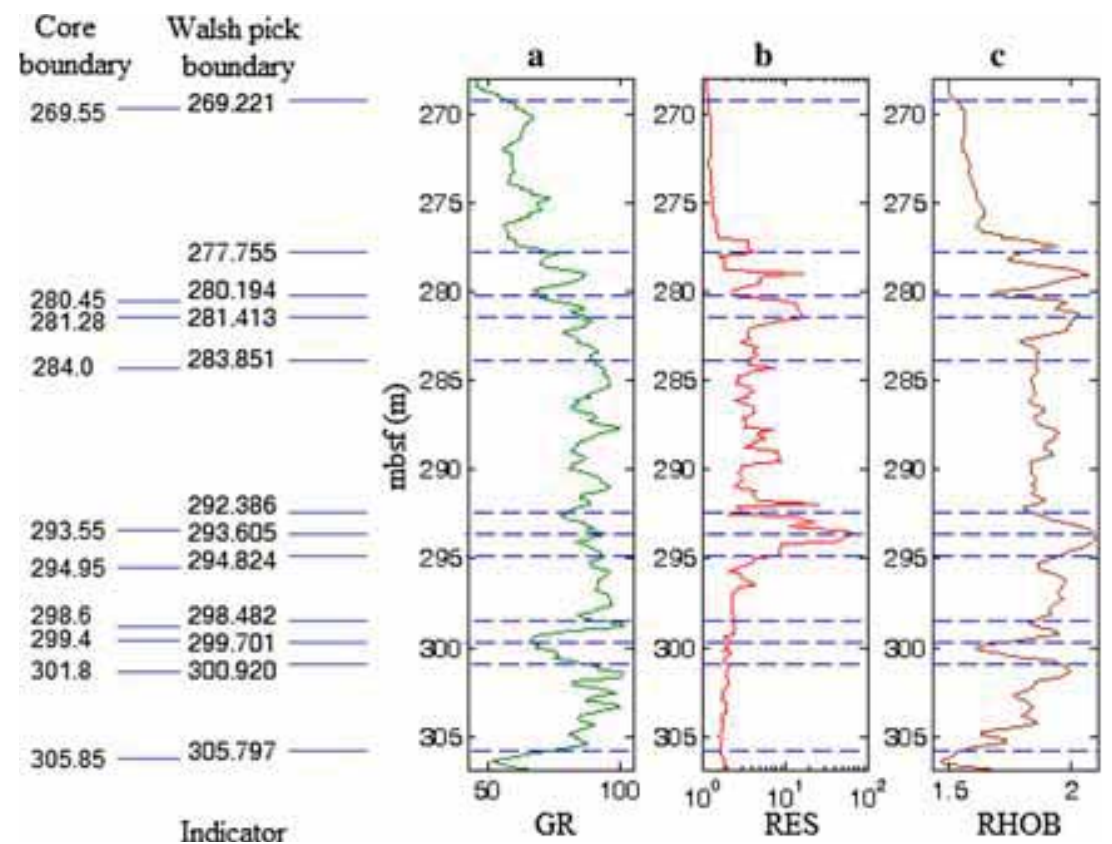

Figure 23. Walsh low pass picked boundaries are plotted over the original log responses at hole NGHP-02-23-C. 
pass operations. The Walsh low pass operation for boundary detection for the holes NGHP-02-17-C, NGHP-02-19-C, NGHP-02-22-C and NGHP-02-23$\mathrm{C}$ is demonstrated in figures 16-19. Where the right panel is associated with the boundary depths labelled as 'Walsh low pass pick'. This pick value is greater or equal to the 'check' value for a specific depth. Therefore, the Walsh pick is a measure of the depth which is being a boundary. Finally, to comprehend the changes of the log signature with the bed boundary position, the 'Walsh low pass picked' boundaries are plotted over three sets of original well log data and compared with available core boundaries (figures 20-23). The details of available core boundaries and Walsh picked boundaries obtained from the wireline log responses of the boreholes NGHP-02-17-C, NGHP-02-19C, NGHP-02-22-C and NGHP-02-23-C are shown in tables 1-4, respectively.

According to this study, the thickness of the thinnest bed from the boreholes NGHP-02-17-C and NGHP-02-23-C is $1.2192 \mathrm{~m}$, whereas, the thickness of the finest bed is $4.876 \mathrm{~m}$ for the boreholes NGHP-02-19-C and NGHP-02-22-C. Unfortunately, we have insufficient core information to support the derived results. Only few discontinuous cores are available, from which we cannot get optimum information regarding the boundary location. Here, we focused only on the changes of log signatures and Walsh picked boundaries.

\section{Conclusions}

To assess the accuracy of the automatic lithological boundary detection, we have compared our results with the existing techniques including that proposed by Maiti and Tiwari (2005). It shows that along with the available core information (boundaries), we have identified additional bed boundaries with the 'Walsh low pass' approach. Thus, the new technique has the ability to identify the finest bed, which is not so easy to recognise in the traditional wireline log interpretation. Therefore, this type of bed boundary detecting method may provide more reliable results than core data for the selected depth interval.

According to our analysis, the finest step length is $1.219 \mathrm{~m}$ and we have identified thin beds of the same order. However, in this technique, the number of detected bed boundaries is 'weight' dependent, and thus subject to the interpreter. It has been observed that if the value of the 'weight' is changed, there is a chance of having either more number of beds or fewer number of beds, which can be identified. Therefore, interpreter must have to choose the weight in such a way that at least a few of the obtained boundaries more or less well corroborated with given geological information or core information. Thus, the interpreter has to be careful while choosing the value of weight to get geologically meaningful results.

The borehole image log can identify the thin bed on a centimetre scale. However, it is costly and cannot even measure the whole depth range of a well, as well as for all wells belonging to a particular reservoir. This specific log is used only in an interesting area. Therefore, instead of using borehole image log, Walsh boundary detection techniques can provide an idea regarding the general assessment of the bed boundary distribution of any reservoir using the routine wireline logs.

With the application of this non-traditional approach, the gas hydrate zones can be identified along with the detection of a higher number of thin beds. The reservoir characterisation and model representation is superior using this new technique than by employing older conventional techniques.

\section{Acknowledgements}

We are thankful to the director, CSIR-National Geophysical Research Institute, Hyderabad for permission (Ref. No: NGRI/Lib/2019/Pub-54), and place a record of gratitude to the Director, Wadia Institute of Himalayan Geology to publish this work. We are grateful to the Ministry of Petroleum and Natural Gas (Government of India), Oil India Limited (OIL), Gas Authority of India Limited (GAIL), Indian Oil Corporation Limited (IOCL) and all other NGHP partner organisations for providing the opportunity to contribute to the NGHP-02 Expedition. The technical and science support from Japan Agency for Marine-Earth Science and Technology (JAMSTEC), United States Geological Survey (USGS), U.S. Department of Energy (US-DOE), the National Institute of Advanced Industrial Science and Technology (AIST), Geotek Coring and Schlumberger is gratefully acknowledged. The author also acknowledges the anonymous reviewers for improving the manuscript. Bappa Mukherjee, gratefully acknowledges the Science and Engineering Research Board (SERB/PDF/2017/ 001331), the Government of India, for sponsoring 
this work. The Ministry of Earth Sciences is acknowledged for extending support in pursuing the research on gas hydrates at CSIR-NGRI. This is contributed to the in-house project MLP-6402$28(\mathrm{KS})$.

\section{References}

Aboosadi Z A, Rooeentan S and Adibifar M 2018 Estimation of subsurface petrophysical properties using different stochastic algorithms in nonlinear regression analysis of pressure transients; J. Appl. Geophys. 154 93-107.

Ali M, Paul S and Chatterjee R 2017 Cleat orientation from ground mapping and image log studies for in-situ stress analysis: Coal bed methane exploration in South Karanpura Coalfield, India; Energy Fuels 31(7) 6812-6824.

Auduson E A 2018 Petro-elastic modelling and characterization of solid-filled reservoirs: Comparative analysis on a Triassic North Sea reservoir; J. Appl. Geophys. 154 29-36.

Bath M 1974 Spectral Analysis in Geophysics; Elsevier, Amsterdam.

Beauchamp K G 1975 Walsh Function and Their Applications; Academic Press, New York.

Chatterjee R, Datta Gupta S and Mandal P P 2017 Fracture and stress orientation from borehole image logs: A case study from Cambay Basin, India; J. Geol. Soc. India 89(5) 573-580.

Choudhury S, Chandrasekar E, Pandey K V and Prasad M 2007 Use of wavelet transform for geophysical well-log data analysis; In: Proceedings of the 15th International Conference on Digital Signal, pp. 647-650. https://doi.org/10. 1109/icdsp.2007.4288665.

Das B and Chatterjee R 2018 Well log data analysis for lithology and fluid identification in Krishna-Godavari Basin, India; Arab. J. Geosci. 11 231-242.

Das B, Chatterjee R, Singha D K and Kumar R 2017 Poststack seismic inversion and attribute analysis in shallow offshore of Krishna-Godavari Basin, India; J. Geol. Soc. India 90 32-40.

Dewan J T 1983 Essentials of Modern open-Hole Log Interpretation; PennWell Publishing Company, Tulsa, OK.

Doveton J H 1986 Log Analysis of Subsurface Geology Concepts and Computer Methods; Wiley, New York.

Gaillot P, Brewer T, Pezard P and Yeh E 2007 Borehole imaging tools - Principles and applications; Scientific Drilling, 5. https://doi.org/10.2204/iodp.sd.5.07s1.2007.

Gogoi T and Chatterjee R 2018 Estimation of petrophysical parameters using seismic inversion and neural network modeling in Upper Assam Basin, India; Geosci. Front. https://doi.org/10.1016/j.gsf.2018.07.002.

Harmuth H F 1968 Sequency filters based on Walsh functions; IEEE Trans. Electromagn. Compat. 10 293-295.

Hsieh B Z, Lewis C and Lin Z S 2005 Lithology identification of aquifers from geophysical well logs and fuzzy logic analysis: Shui-Lin Area, Taiwan; Comput. Geosci. 31 263-275.

Jianping Y, Hongpeng Y and Haiyun X 2011 Identifying fracture by time-frequency analysis of well logs; In: International Conference on Computational and Information Sciences (ICCIS), pp. 652-654.

Keating P 1992 Density mapping from gravity data using the Walsh transform; Geophysics $\mathbf{5 7}$ 637-642.

Khoshbakht F, Rasaie M R and Shekarifard A 2017 Improving petrophysical interpretation of conventional log by determination of real bed boundaries; J. Sci. Islamic Repub. Iran 28(2) 147-154.

Kumar P, Yamada Y, Furutani A, Vishwanath K and Collett $\mathrm{T}$ and NGHP-02 Operation \& Science Party 2016 India National Gas Hydrate Program R \& D Expedition 02 Comprehensive Post Expedition Report.

Lanning E N and Johnson D M 1983 Automated identification of rock boundaries: An application of the Walsh transform to geophysical well-log analysis; Geophysics $\mathbf{4 8}$ 197-205.

Maiti S and Tiwari R K 2005 Automatic detection of lithologic boundaries using the Walsh transform: A case study from the KTB borehole; Comput. Geosci. 31(8) 949-955.

Maiti S and Tiwari R K 2012 Modeling of rock boundary using Walsh domain sequency filtering: An example from the German Continental Deep Drilling Program (KTB) borehole site; In: 9th Biennial International Conference $\mathcal{E}$ Exposition on Petroleum Geophysics, P-19, pp. 1-7.

Mukherjee B and Roy P N S 2016 Comparative study of unconventional tools in reservoir characterisation. Case study from Bhogpara, N-E, India; J. Geophys. 37(2) 65-75.

Pal C P 1991 A Walsh sequency filtration method for integrating the resistivity $\log$ and sounding data; Geophysics 56(8) 1259-1266.

Shaw R K and Agarwal B N P 1990 The application of Walsh transforms to interpret gravity anomalies due to some simple geometrically shaped causative sources: A feasibility study; Geophysics $\mathbf{5 5}$ 843-850.

Shaw R K, Agarwal B N P and Nandi B K 1998 Walsh spectra of gravity anomalies over some simple sources; J. Appl. Geophys. 40 179-186.

Singha D K and Chatterjee R 2015 Geomechanical modeling using finite element method for prediction of in-situ stress in Krishna-Godavari basin, India; Int. J. Rock Mech. Min. 73 15-27.

Singha D and Chatterjee R 2017 Rock physics modeling in sand reservoir through well log analysis, Krishna-Godavari basin, India; Geomech. Eng. 13(1) 99-117.

Singha D K, Chatterjee R, Sen M K and Sain K 2014 Pore pressure prediction in gas-hydrate bearing sediments of Krishna-Godavari Basin in, India; Mar. Geol. 357 1-11.

Wu W and Grana D 2017 Integrated petrophysics and rock physics modeling for well log interpretation of elastic, electrical, and petrophysical properties; J. Appl. Geophys. 146 54-66. 